\title{
Exploring the abundance of oleate hydratases in the genus Rhodococcus-discovery of novel enzymes with complementary substrate scope
}

\author{
Hanna Busch ${ }^{1} \cdot$ Fabio Tonin ${ }^{1}$ (D) * Natália Alvarenga ${ }^{1}$ (D) $\cdot$ Marcel van den Broek ${ }^{1} \cdot$ Simona Lu $^{1} \cdot$ Jean-Marc Daran ${ }^{1}$ (D) \\ Ulf Hanefeld ${ }^{1}$ (1) - Peter-Leon Hagedoorn ${ }^{1}$ (i)
}

Received: 5 October 2019 / Revised: 2 April 2020 / Accepted: 14 April 2020 / Published online: 1 May 2020

(C) The Author(s) 2020

\begin{abstract}
Oleate hydratases (Ohys, EC 4.2.1.53) are a class of enzymes capable of selective water addition reactions to a broad range of unsaturated fatty acids leading to the respective chiral alcohols. Much research was dedicated to improving the applications of existing Ohys as well as to the identification of undescribed Ohys with potentially novel properties. This study focuses on the latter by exploring the genus Rhodococcus for its plenitude of oleate hydratases. Three different Rhodococcus clades showed the presence of oleate hydratases whereby each clade was represented by a specific oleate hydratase family (HFam). Phylogenetic and sequence analyses revealed HFam-specific patterns amongst conserved amino acids. Oleate hydratases from two Rhodococcus strains (HFam 2 and 3) were heterologously expressed in Escherichia coli and their substrate scope investigated. Here, both enzymes showed a complementary behaviour towards sterically demanding and multiple unsaturated fatty acids. Furthermore, this study includes the characterisation of the newly discovered Rhodococcus pyridinivorans Ohy. The steady-state kinetics of $R$. pyridinivorans Ohy was measured using a novel coupled assay based on the alcohol dehydrogenase and NAD ${ }^{+}$ dependent oxidation of 10-hydroxystearic acid.
\end{abstract}

Keywords Fatty acid hydratase $\cdot$ Enzyme assay $\cdot$ Oleate hydratase $\cdot$ Rhodococcus $\cdot$ Water addition

\section{Introduction}

Rhodococcus is a genus of aerobic, gram-positive bacteria and is known for its diverse biocatalytic activity towards a plethora of substrates (van der Geize and Dijkhuizen 2004; Jones and Goodfellow 2012; Kim et al. 2018; Busch et al. 2019). Aliphatic, aromatic or heterocyclic compounds as well as alicyclic hydrocarbons, cholesterol, nitriles and lignin have been shown to be converted by members of the versatile Rhodococcus family (van der Geize and Dijkhuizen 2004; Kim et al. 2018). The reason for their catabolic adaptability is explained by interacting factors such as their large genome

Electronic supplementary material The online version of this article (https://doi.org/10.1007/s00253-020-10627-7) contains supplementary material, which is available to authorized users.

Peter-Leon Hagedoorn

P.L.Hagedoorn@tudelft.nl

1 Department of Biotechnology, Delft University of Technology, Van der Maasweg 9, 2629 HZ Delft, The Netherlands sizes, the redundancy of biosynthetic pathways and the presence of large, linear plasmids often harbouring multiple copies of genes encoding degrading enzymes (van der Geize and Dijkhuizen 2004; Alvarez 2019; Zampolli et al. 2019).

The immense progress made in genomic studies enables a fast and extensive processing of bacterial genome information to designate gene functions to undescribed enzymes (Zampolli et al. 2019). This helps identifying novel biocatalysts in e.g. Rhodococcus and therefore increases the biotechnological potential for this catalytic powerhouse. One enzyme family that receives increasing attention is the class of hydratases (E.C. 4.2.1.x) which belong to the group of lyases. They catalyse the reversible water addition to $\pi$-bond systems and can be categorised in two groups based on their substrate scope: isolated double bonds or conjugated systems (Resch and Hanefeld 2015; Engleder and Pichler 2018).

Oleate hydratase (Ohy) belongs to the first group acting on isolated double bonds in fatty acids e.g. oleic acid to produce 10-hydroxystearic acid (Scheme 1) (Demming et al. 2018; Engleder and Pichler 2018; Serra et al. 2020). Up until now, all characterised Ohys are FAD-dependent. However, the 
precise role of FAD in the protein remains not fully understood (Engleder and Pichler 2018).

With the newly developed 'Hydratase Engineering Database', it is now possible to distinguish 11 homologous families (HFam) of fatty acid hydratases (Schmid et al. 2016). Sequence comparison of 2046 hydratase sequences exposed the presence of the 11 families ('HFam 1 to $11^{\text {') }}$ whose members share an average sequence identity of $62 \%$. With 1188 sequences, HFam 2 makes the largest group followed by HFam 1 and HFam 3 (Schmid et al. 2016).

Recently, the first Ohy from Rhodococcus was characterised and the structure elucidated (Lorenzen et al. 2017). The protein belongs to HFam 3 and thereby offers the first structural insight into a representative of this hydratase family. Unlike the other three crystallographically resolved Ohys which were all shown to be homodimers (Volkov et al. 2013; Engleder et al. 2015; Park et al. 2018), this protein has been described to be an active monomer in solution. The characterised Ohy from $R$. erythropolis CCM 2595, ReOhy (CCM 2595), catalyses the conversion of a number of fatty acids exclusively in 10-position yielding the respective hydroxylated fatty acids (Lorenzen et al. 2017). This example again serves to show the rich abundance of diverse biocatalytic activities within Rhodococcus and demonstrates the possibilities of finding novel biocatalysts within this genus.

The aim of this study is to investigate the abundance of oleate hydratases within the genus Rhodococcus. An Orthologous Matrix (OMA) was established from multiple Rhodococcus strains whose data was made either publicly available or sequenced in-house. Through genome mining of those 43 Rhodococcus strains, 20 annotated oleate hydratases were revealed. Subsequently, the discovered oleate hydratases were analysed phylogenetically and categorised based on their HFam affiliation. Thereby, overall, three different groups of oleate hydratases have been distinguished (HFam 1 to 3 ) in Rhodococcus. One representative of each HFam 2 and HFam 3 was selected for heterologous expression, and an extensive whole-cell substrate screening was carried out to investigate differences in substrate acceptance. Additionally, the thereby

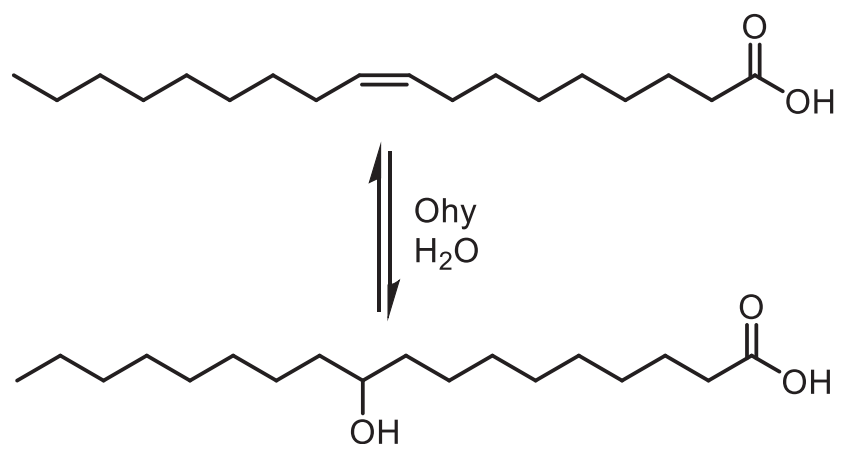

Scheme 1 Oleate hydratase catalysed water addition to oleic acid (18:1, cis-9) yielding 10-hydroxystearic acid newly discovered Ohy from Rhodococcus pyridinivorans DSM 20415 (HFam 2) was characterised and the properties were compared with the earlier described ReOhy (CCM 2595) (HFam 3) (Lorenzen et al. 2017). As part of this characterisation, a novel enzyme assay for Ohys was developed.

\section{Material and methods}

\section{Chemicals}

All commercial chemicals were purchased from SigmaAldrich (Schnelldorf, Germany). The UltraClean Microbial DNA Isolation Kit was purchased from MOBIO Laboratories, Inc. (Uden, The Netherlands). (R)-10hydroxystearic acid was obtained from InnoSyn (Geleen, The Netherlands; kind gift by Dr. Martin Schürmann).

\section{Bacterial strains and microorganisms}

The Rhodococcus pyridinivorans DSM 20415 was purchased from the German Collection of Microorganisms and Cell Culture (Leibniz Institute DMSZ). Plasmid pBAD/His A and Escherichia coli TOP10 cells were obtained from Fisher Scientific (Landsmeer, The Netherlands). The GenBank accession numbers for the original and codon-optimised (including His-tag) nucleotide sequences of $R p$ Ohy are MN563120 and MN563121 respectively.

\section{Genomic DNA extraction}

The genomic DNA of the strain $R$. pyridinivorans DSM 20415 was isolated from a cell pellet $(50-100 \mathrm{mg}$ ) using the UltraClean Microbial DNA Isolation Kit following standard procedure.

\section{Whole-genome sequencing}

Genomic DNA of $R$. pyridinivorans DSM 20415 was inhouse sequenced on a MiSeq sequencer (Illumina, San Diego, CA) to obtain a 300 cycle paired-end library with an insert size of $550 \mathrm{bp}$ using PCR-free library preparation, yielding 2.6 gigabases in total. De novo assembly was performed using SPAdes (version 3.9.0) (Bankevich et al. 2012). The assembled genome of $R$. pyridinivorans DSM 20415 were annotated by using Prokka (version 1.12) (Seemann 2014).

\section{Orthologous Matrix (OMA) and phylogenetic analysis}

Pairwise orthologues of the proteome of the annotated genome were computed using the Orthologous Matrix (OMA) software (standalone version 2.2.0) (Train et al. 2017). A species tree was inferred based on the $1 \%$ most complete 
computed orthologous groups. MEGA (version 7.0.21) was used for visualization. Ohy protein sequences were aligned using MUSCLE (version 3.8.31) (Edgar 2004). Distance matrix was calculated by FastTree (version 2.1.9, JTT+CAT model) and then visualized by MEGA (Price et al. 2010).

\section{Cloning}

The Ohy coding genes from Rhodococcus erythropolis PR4 (ReOhy (PR4)) and from Rhodococcus pyridinivorans DSM 20415 (RpOhy) were used as templates for codon-optimised gene synthesis (BaseClear B.V., Leiden, NL). Both synthetic genes (ReOhy (PR4) and RpOhy) were sub-cloned in pBAD/His A expression vectors and subsequently transformed into $E$. coli TOP10 cells following standard procedures.

\section{Protein expression and purification}

ReOhy (PR4) and RpOhy were expressed in E. coli TOP10 cells grown on LB medium. Pre-cultures were inoculated with a single colony and grown overnight at $37{ }^{\circ} \mathrm{C}$ with orbital shaking (180 rpm, Innova44, New Brunswick Scientific). The main cultures ( 11 in a 5-1 baffled shake flask) were inoculated with $5 \mathrm{ml}$ of pre-culture and grown to an optical density of $0.6-0.8$ at $37{ }^{\circ} \mathrm{C}$ with orbital shaking (180 rpm). The protein expression was induced by adding L-arabinose with a final concentration of $0.2 \%$. After $16 \mathrm{~h}$ of growth at $25{ }^{\circ} \mathrm{C}$, cells were harvested $\left(15 \mathrm{~min}, 4{ }^{\circ} \mathrm{C}, 17,700 \mathrm{~g}\right)$, washed with $20 \mathrm{mM}$ Tris- $\mathrm{Cl}(\mathrm{pH} 8)$ and kept at $20^{\circ} \mathrm{C}$. Frozen cell pellets of $R p$ Ohy were thawed, resuspended in $20 \mathrm{mM}$ Tris- $\mathrm{Cl}(\mathrm{pH} 8)$ and disrupted by high pressure homogenisation (Constant Systems Ltd., UK). Subsequent centrifugation (15 min, $4{ }^{\circ} \mathrm{C}, 17,700 \mathrm{~g}$ ) yielded cell debris and soluble protein fraction. The supernatant was applied on a $\mathrm{Ni}^{2+}$-NTA His-trap column (HisTrap FF, GE Healthcare, flow rate $1 \mathrm{ml} / \mathrm{min}$ ) and purified on a NGC chromatography system (Bio-Rad Laboratories, Inc., US). The purified protein solution was desalted using a PD10 desalting column. The His-tag-purified $R p$ Ohy was afterwards separately applied on a HiLoad 26/60 Superdex 200 prep grade size-exclusion column (flow rate $2 \mathrm{ml} / \mathrm{min})$. Respective fractions were collected and concentrated.

Oleate hydratase from Elisabethkingia meningoseptica (Em-OAH1) was expressed as a His-tagged protein using E. coli $\mathrm{pBAD} / \mathrm{His} \mathrm{A}-\mathrm{ohyA}$ as previously described (Bevers et al. 2009). The enzyme was purified as described above for RpOhy.

\section{Fatty acid screening}

For the fatty acid screening, E. coli TOP10 whole cells with overexpressed $R p$ Ohy, ReOhy (PR4) or with an empty
$\mathrm{pBAD} /$ His A expression vector were resuspended to a wetcell content of $100 \mathrm{mg} / \mathrm{ml}$ in $50 \mathrm{mM}$ Tris-Cl, pH 7.5, supplemented with $50 \mathrm{mM}$ glucose. Fatty acid stocks were dissolved with co-solvent DMSO (1\% final concentration in the reaction). To each reaction, $0.2 \mathrm{mM}$ FAD, $5 \mathrm{mM}$ DTT and $5 \mathrm{mM}$ NADH were added. These chosen conditions lead to an FAD reducing environment which has been shown to be beneficial as Ohy reportedly is more active in the presence of reduced $\mathrm{FADH}_{2}$ compared with oxidised FAD (Engleder et al. 2015; Demming et al. 2017). Reactions $(500 \mu \mathrm{l})$ were started by substrate addition $(500 \mu \mathrm{M})$ and were carried out with orbital shaking $(800 \mathrm{rpm})$ at $30^{\circ} \mathrm{C}$ for 6 days (Demming et al. 2017; Engleder et al. 2019). All reactions were performed in triplicate. Additionally, each reaction was flushed with $\mathrm{N}_{2}$ to avoid oxidation of unsaturated fatty acids.

\section{RpOhy characterisation}

For the standard small-scale biotransformations with purified enzyme, $R p$ Ohy $(5 \mu \mathrm{M})$ was diluted in $20 \mathrm{mM}$ acetate buffer, pH 5 (200 $\mu$ l final volume) and $20 \mu \mathrm{M}$ FAD was added. Reactions were started by substrate addition $(500 \mu \mathrm{M}$ oleic acid with $1 \%$ DMSO) and run for $5 \mathrm{~h}$ at $25{ }^{\circ} \mathrm{C}$ with orbital shaking $(800 \mathrm{rpm})$. The temperature optimum was determined in the range of $20^{\circ} \mathrm{C}$ to $60{ }^{\circ} \mathrm{C}$ with reactions run in acetate buffer $(20 \mathrm{mM}, \mathrm{pH} 5)$. The $\mathrm{pH}$ optimum was investigated in the $\mathrm{pH}$ range of 3.6 to 10 at $25^{\circ} \mathrm{C}$. The following buffers were used (20 mM): pH 3.6-5 (acetate buffer), pH 5-6 (citrate buffer), $\mathrm{pH}$ 6-7.5 (potassium phosphate buffer), $\mathrm{pH} 7.2-8$ (Tris-Cl buffer) and pH 8-10 (carbonate-bicarbonate buffer).

\section{Development of a novel oleate hydratase enzyme kinetic assay}

In order to determine $R p$ Ohy kinetic parameters, a novel coupled assay was developed based on the ability of an alcohol dehydrogenase (ADH) to oxidise the product 10 hydroxystearic acid with concomitant reduction of $\mathrm{NAD}^{+}$to NADH. A commercially available screen of ten different $\mathrm{NAD}^{+}$-dependent ADHs (Evoxx, Monheim am Rhein, Germany), supplied as lyophilised powders, was used to identify enzymes capable of oxidising 10-hydroxystearic acid. The following reaction conditions were used: $0.47 \mathrm{mg} / \mathrm{ml}$ enzyme (lyophilised powder), $2.5 \mathrm{mM}$ 10-hydroxystearic acid, $2 \mathrm{mM}$ $\mathrm{NAD}^{+}, 20 \mathrm{mM}$ PIPES buffer $\mathrm{pH} 6.5$ and 10\% DMSO. Initial rates of formation of NADH were measured spectrophotometrically at $340 \mathrm{~nm}$ using a 96-well plate reader (BioTek) and using $\varepsilon_{340}(\mathrm{NADH})=6.2 \mathrm{mM}^{-1} \mathrm{~cm}^{-1}$. The most active ADH under these conditions (ADH010) was used to validate the coupled assay with the well-established Ohy from Elisabethkingia meningoseptica (Em-OAH1) using the following conditions: $0-0.5 \mathrm{mg} / \mathrm{ml}$ ADH010, $0-2 \mathrm{mg} / \mathrm{ml}$ Em-OAH1, $2.5 \mathrm{mM}$ oleic acid, $2 \mathrm{mM} \mathrm{NAD}{ }^{+}, 50 \mathrm{mM}$ PIPES 
buffer pH 6.5 and 10\% DMSO. Successful conditions for the coupled Ohy-ADH assay were subsequently applied to determine the kinetic parameters of RpOhy. The coupled assay conditions were the following: $200 \mu$ l reaction mixture containing $0.125-2.5 \mathrm{mM}$ oleic acid, $2 \mathrm{mM}$ $\mathrm{NAD}^{+}, 50 \mathrm{mM}$ PIPES pH 6.5 and $10 \%$ DMSO. The reactions were started by the addition of $0.3-$ $1.5 \mu \mathrm{g} / \mathrm{ml} R p$ Ohy and $0.01-0.5 \mathrm{mg} / \mathrm{ml}$ ADH010. The reactions were followed spectrophotometrically at $340 \mathrm{~nm}$ for $10 \mathrm{~min}$. The initial rates were plotted versus the oleic acid concentration and apparent kinetic parameters were determined using the Hill equation for enzyme kinetics.

\section{Sample derivatisation}

All reactions were quenched by the addition of $20 \mu \mathrm{l}$ of $1 \mathrm{M}$ $\mathrm{HCl}$ after the respective reaction time. Reactions were extracted with an equal ethyl acetate (EtOAc) volume before derivatisation. A total of $100 \mu \mathrm{l}$ of extraction mixture was derivatised with $200 \mu$ of derivatising agent (1:1 pyridine: $N, O$-bis(trimethylsilyl)trifluoroacetaminde (BSTFA)) with $1 \%$ trimethyl-silylchloride (TMSCl) for $1 \mathrm{~h}$ at $60{ }^{\circ} \mathrm{C}$

\section{Sample analysis}

Achiral GC-FID analysis of the derivatised hydroxylated fatty acids was performed with a Shimadzu type GC-2014 equipped with a CP-Sil5 CB column $(50 \mathrm{~m} \times 0.53 \mathrm{~mm} \times$ $1.0 \mu \mathrm{m})$ using $\mathrm{N}_{2}$ as carrier gas. The following conditions were used for the achiral separation using direct injection: injector $340{ }^{\circ} \mathrm{C}$, detector (FID) $360{ }^{\circ} \mathrm{C}$, column flow rate $20.0 \mathrm{ml} / \mathrm{min}$, temperature program: start at $130^{\circ} \mathrm{C}$, hold time $4 \mathrm{~min}$, rate $15^{\circ} \mathrm{C} / \mathrm{min}$ to $330{ }^{\circ} \mathrm{C}$ hold time $5 \mathrm{~min}$.

Gas chromatography-mass spectrometry of derivatised hydroxylated fatty acids was performed with the Shimadzu GC2010 system which is connected to the GCMS-QP2010s mass detector from Shimadzu. The column CP-Sil5 CB (25 $\mathrm{m} \times$ $0.25 \mathrm{~mm} \times 0.4 \mu \mathrm{m})$ was used. Injections were performed with the autoinjector AOC-20i from Shimadzu. The injector temperature was kept at $250{ }^{\circ} \mathrm{C}$. The injector was used in split-mode with a split ratio of $30: 1$ at a pressure of $51.2 \mathrm{kPa}$. The temperature program for fatty acids 1 and 3-15: start at $130{ }^{\circ} \mathrm{C}$, hold time $4 \mathrm{~min}$, rate $15{ }^{\circ} \mathrm{C} / \mathrm{min}$ to $330{ }^{\circ} \mathrm{C}$ hold time $5 \mathrm{~min}$; temperature program for fatty acid 2: start at $130{ }^{\circ} \mathrm{C}$, hold time $4 \mathrm{~min}$, rate $5{ }^{\circ} \mathrm{C} / \mathrm{min}$ to $325{ }^{\circ} \mathrm{C}$ hold time $7 \mathrm{~min}$. Structure determination was based on the comparison of monomer peaks using external standards.

Databases Bioproject accession number PRJNA555451. GenBank accession numbers MN563120 and MN563121.

\section{Results}

\section{Extending the data set of an Orthologous Matrix (OMA) algorithm to identify novel biocatalysts}

In the course of identifying novel hydratases with interesting properties in the genus Rhodococcus, an Orthologous Matrix (OMA) algorithm approach was used combining a large number of Rhodococcus strains from different families. The strain $R$. pyridinivorans DSM 20415 showed interesting behaviour towards $\alpha, \beta$-unsaturated Michael acceptors in previous studies (Busch et al. 2020). As no genomic sequence data was available, it was decided to sequence the whole genome to subsequently incorporate this interesting strain into the generated Orthologous Matrix algorithm to further investigate whether this strains also produces an Ohy. The strain R. pyridinivorans DSM 20415 was originally isolated from activated sludge from a wastewater treatment plant (Mimura et al. 1969a, b).

The genome shows a size of 5,275,644 bp with a GC content of $67.7 \%$. More detailed information on the sequence can be found in the Supplementary Information (Table S1), and the complete sequencing data is available at NCBI under bioproject accession number PRJNA555451. Protein and amino acid sequence of $R p$ Ohy are given in the Supplementary information.

\section{Orthologous Matrix algorithm analysis of oleate hydratases in the genus Rhodococcus}

High-quality whole-genome sequences (WGS) from 43 Rhodococcus strains were either obtained by sequencing (in the case of $R$. pyridinivorans DSM 20415) or were publicly available from the National Centre for Biotechnology Information (NCBI) (Geer et al. 2009). Whole-genome sequences were analysed with the Orthologous Matrix (OMA) software (standalone version 2.2.0) using an improved matrix algorithm to generate pairwise orthologues of the proteomes of the annotated genomes (Altenhoff et al. 2013; Kumar et al. 2016). Within the 43 investigated strains, 20 oleate hydratases were identified. In total, three different HFams were recognised by the 'Hydratase Engineering Database': HFam 1, 2 and 3 (Schmid et al. 2016).

All investigated $R$. equi strains display an oleate hydratase from HFam 1. The largest group consists of 11 strains (including all $R$. erythropolis and all $R$. qingshengii, $R$. enclensis NIO-1009, R. rhodochrous DSM 101666 and $R$. rhodochrous ATCC 17895 as well as Rhodococcus $\mathrm{R} 312$ ) displaying an oleate hydratase from HFam 3. On the other hand, all $R$. pyridinivorans strains as well as the $R$. biphenylivorans TG9 show an oleate hydratase from HFam 2. Interestingly, one strain, $R$. erythropolis DSM 
43066, displays two oleate hydratases with one belonging to HFam 2 and the other one to HFam 3 (Table S2).

To investigate the relation between the strains, a phylogenetic tree was created based on the $1 \%$ of most complete computed orthologous groups and visualised with MEGA (Fig. 1) (Kumar et al. 2016; Train et al. 2017). Similar results were obtained when a phylogenetic tree was based on the $16 \mathrm{~S}$ rRNA sequences (Fig. S1). As clearly visible, the three groups inheriting the same type of oleate hydratase cluster together. They form three independent clades from now on called 'erythropolis-clade' (green), 'pyridinivorans-clade' (blue) and 'equi-clade' (red).

To analyse the relation between the annotated oleate hydratases amongst the different families, a phylogenetic tree was generated (Fig. S2). R. erythropolis DSM 43066 is the only strain with two different types of oleate hydratase present. While the ' $R$. erythropolis'- and ' $R$. equi'-clade are built up uniformly, the oleate hydratase from $R$. erythropolis DSM 43066 forms its own sub-group within the ' $R$. pyridinivorans'-clade. To identify similarities and distinct differences between the three oleate hydratase groups, a
Fig. 1 Phylogenetic tree of 43 investigated Rhodococcus strains based on the $1 \%$ of most complete computed orthologous groups (Kumar et al. 2016; Train et al. 2017). HFam 2 or

' $R$. pyridinivorans'-clade highlighted in blue, HFam 1 or 'R. equi'-clade in red and HFam 3 or ' $R$. erythropolis'-clade in green

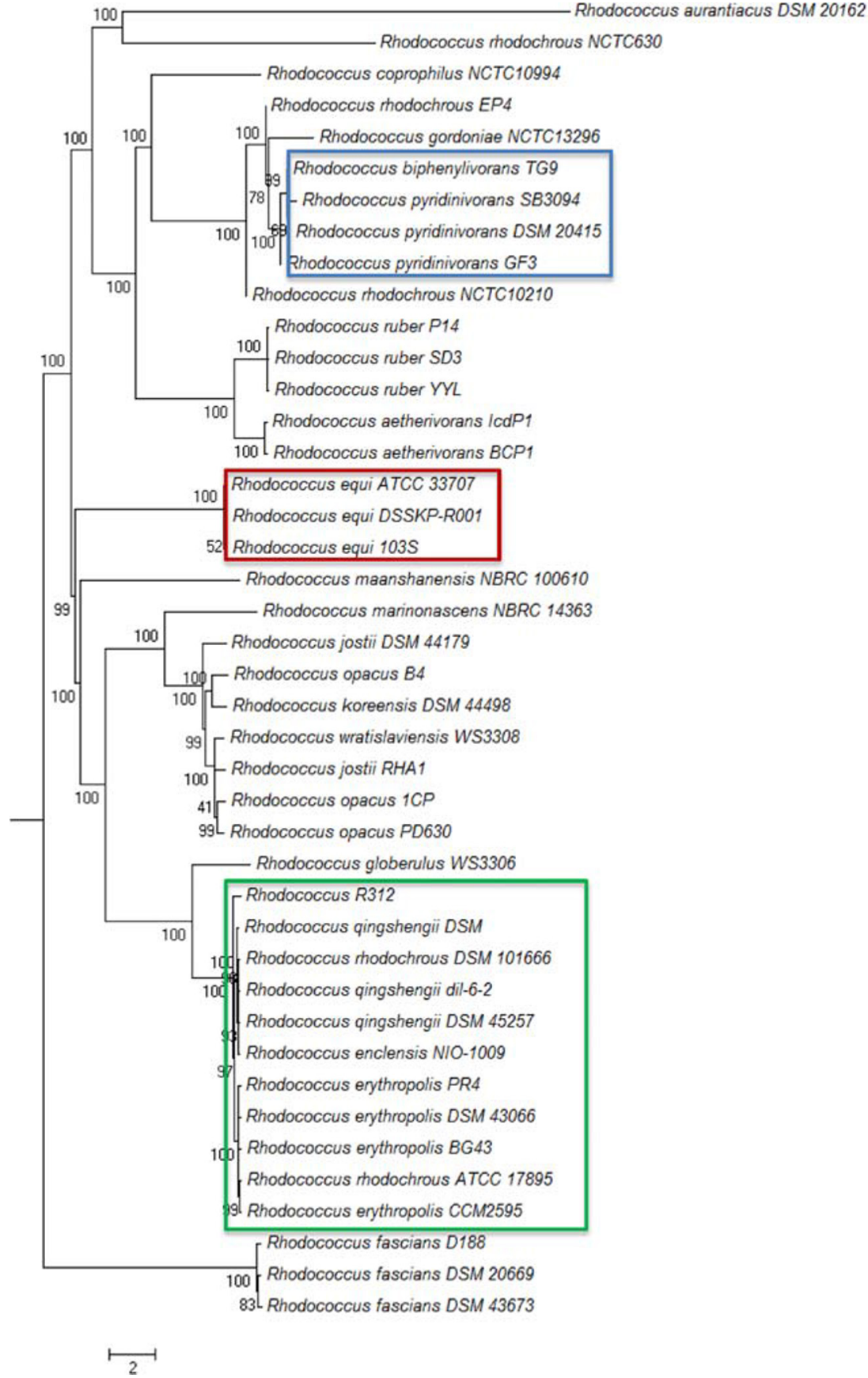


sequence alignment was performed to study the specific conservation pattern.

\section{Fatty acid substrate specificity of ReOhy (HFam 3) and RpOhy (HFam 2)}

A number of fatty acid substrates were tested for activity using E. coli whole cells overexpressing RpOhy (DSM 20415), ReOhy (PR4) as well as E. coli TOP10 cells containing an empty $\mathrm{pBAD} / \mathrm{His} \mathrm{A}$ expression vector as negative control. Due to recent reports about the benefits of applying wholecell systems over cell-free extract or purified enzymes such as a higher operational stability, the prevention of time-consuming steps like protein purification and therefore an overall easier handling, all reactions were carried out in a whole-cell system (Demming et al. 2017; Engleder et al. 2019). All reactions using E. coli TOP10 cells bearing the empty $\mathrm{pBAD} / \mathrm{His} \mathrm{A}$ vector did not show any product formation ruling out background hydration activity. Fifteen fatty acids were tested with representatives from $R$. pyridinivorans DSM 20415 (RpOhy, HFam 2) and from $R$. erythropolis PR4 (ReOhy (PR4), HFam 3, Table 1, molecular structures Table S3). If applicable, these whole-cell screening results were compared with the earlier described ReOhy (CCM2595, HFam 3) substrate screening using purified enzyme by Lorenzen et al. (2017).
Three substrates were converted by neither of the tested Ohys: nervonic acid as well as cis- and trans-vaccenic acid. Myristoleic acid was converted by both ReOhy (PR4) and $R p$ Ohy (DSM 20415) under the chosen whole-cell conditions. While $R e$ Ohy (PR4) did not show any activity towards ricinoleic acid, $R p$ Ohy produced the 10,12-dihydroxylated fatty acid. Fatty acids 10-13 all carry a cis-double bond in 11-position as does $c i s$-vaccenic acid. While $R p$ Ohy only converted cis-11-eicosenoic acid (10) with low activity, ReOhy (PR4) showed activity towards all four long, unsaturated fatty acids leading to the mono-hydrated 12-hydroxy fatty acids, exclusively. $R e$ Ohy (PR4) is therefore, to our knowledge, the first Ohy being able to selectively catalyse the water addition to long-chain, unsaturated fatty acids selectively in 12-position. Chromatograms comparing conversions of RpOhy and $R e$ Ohy (PR4) as well as the GC-MS data of hydroxylated fatty acids can be found in the Supplementary Information (Figs. S6-S29).

\section{RpOhy (DSM 20415) characterisation}

The Ohy from $R$. pyridinivorans DSM 20415 has a calculated protein weight of $67.8 \mathrm{kDa}$ and consists of 601 amino acids. After heterologous expression in E. coli TOP10 cells, the Nterminally His6-tagged enzyme was purified by $\mathrm{Ni}^{2+}$-affinity chromatography and a subsequent size-exclusion chromatography (SEC). SEC revealed the presence of multiple

Table 1 Tested substrates and position of hydroxyl group in product of RpOhy (DSM 20415) and ReOhy (PR4) whole-cell substrate screening. All reactions were performed in triplicate

\begin{tabular}{|c|c|c|c|c|c|}
\hline Entry & Substrate & & Rp Ohy ${ }^{\mathrm{a}}$ & $\operatorname{ReOhy}(\mathrm{PR} 4)^{\mathrm{a}}$ & ReOhy $(\mathrm{CCM} 2595)^{\mathrm{b}}$ \\
\hline 1 & Myristoleic acid & $14: 1$, cis -9 & 10 & 10 & $--^{c}$ \\
\hline 2 & Palmitoleic acid & $16: 1$, cis-9 & 10 & 10 & 10 \\
\hline 3 & Oleic acid & $18: 1$, cis -9 & 10 & 10 & 10 \\
\hline 4 & Linoleic acid & $18: 2$, cis $-9,12$ & 10 & 10 & 10 \\
\hline 5 & Pinolenic acid & $18: 3$, cis-5,9,12 & 10 & 10 & Unknown $^{\mathrm{d}}$ \\
\hline 6 & cis-Vaccenic acid & $18: 1, c i s-11$ & $--^{c}$ & $--^{c}$ & $--^{c}$ \\
\hline 7 & trans-Vaccenic acid & $18: 1$, trans -11 & $--^{c}$ & $--^{c}$ & unknown $^{\mathrm{d}}$ \\
\hline 8 & $\gamma$-Linolenic acid & $18: 3$, cis $-6,9,12$ & 10 & 10 & 10 \\
\hline 9 & Ricinoleic acid & $18: 1$, cis-9, $(R)-12-\mathrm{OH}$ & 10 & $--^{c}$ & unknown $^{\mathrm{d}}$ \\
\hline 10 & cis-11-Eicosenoic acid & $20: 1, c i s-11$ & 12 & 12 & unknown $^{\mathrm{d}}$ \\
\hline 11 & cis-8,11-Eicosadienoic acid & $20: 2$, cis- 8,11 & $--^{c}$ & 12 & unknown $^{\mathrm{d}}$ \\
\hline 12 & cis-8,11,14-Eicosatrienoic acid & $20: 3$, cis- $8,11,14$ & $--^{c}$ & 12 & $--^{c}$ \\
\hline 13 & cis-5,8,11,14-Eicosatetraenoic acid (arachidonic acid) & $20: 4$, cis- $5,8,11,14$ & $--^{c}$ & 12 & $--^{c}$ \\
\hline 14 & Erucic acid & $22: 1, c i s-13$ & $--^{c}$ & 14 & unknown $^{\mathrm{d}}$ \\
\hline 15 & Nervonic acid & $24: 1, c i s-15$ & $--^{c}$ & $--^{c}$ & unknown $^{\mathrm{d}}$ \\
\hline
\end{tabular}

${ }^{\text {a }}$ Position of hydroxyl group determined by GC-MS.

${ }^{\mathrm{b}}$ Position of hydroxyl group and substrate acceptance determined by Lorenzen et al. (2017)

${ }^{\mathrm{c}}$ No water addition

${ }^{\mathrm{d}}$ Not tested 
oligomeric states, predominantly monomeric and dimeric with additional larger aggregates (>10 meric) whose ratios were shown to be independent on the enzyme concentration used (Fig. S30 and Table S4). The purified protein had a yellow colour indicating that the FAD cofactor was incorporated in the enzyme after the purification. The standard activity of $R p$ Ohy was measured by following the conversion of oleic acid to 10-hydroxystearic acid for $5 \mathrm{~h}$.

A beneficial effect of FAD addition to the reaction mixture was investigated in the range of $0-100 \mu \mathrm{M}$. Even without any addition of FAD, product formation (35\%) was observed, but the addition of FAD increased the activity. However, the amount of added FAD $(10-100 \mu \mathrm{M})$ did not have a significant impact on the product formation (51-57\%) (Figs. S31 and $\mathrm{S} 32)$. Therefore, it was decided to add $20 \mu \mathrm{M}$ to ensure a fully FAD-saturated protein in all bioconversions. The temperature tolerance for $R p$ Ohy was measured in a range from 15 to $60{ }^{\circ} \mathrm{C}$ (Fig. 2). The highest activity was achieved at $25^{\circ} \mathrm{C}$, but the protein remained active in a broad temperature range from $15^{\circ} \mathrm{C}$ to $40^{\circ} \mathrm{C}$. Higher temperatures, however, led to its deactivation.

The $\mathrm{pH}$ acceptance of $\mathrm{RpOhy}$ was investigated in the $\mathrm{pH}$ range of 3.6-10 (Fig. 3). The highest activity was determined at $\mathrm{pH} 5$ (acetate buffer, $20 \mathrm{mM}$ ). The protein remained active over a broad $\mathrm{pH}$ range from $\mathrm{pH}$ 5-8.

\section{Development of a novel sensitive oleate hydratase kinetic assay}

In order to determine the kinetic parameters of $R p O h y$, a novel assay was established to allow sensitive and straightforward rate measurements in the sub-mM substrate concentration range. The assay is based on the coupling of the hydration of oleic acid to 10-hydroxystearic acid by Ohy with the subsequent oxidation of 10-hydroxystearic acid to 10-ketostearic acid by an $\mathrm{NAD}^{+}$-dependent $\mathrm{ADH}$, which allows the spectrophotometric measurement of $\mathrm{NAD}^{+}$reduction. A commercial screen of ten different $\mathrm{NAD}^{+}$-dependent ADHs was used and two enzymes, ADH010 and ADH020, which efficiently oxidise 10-hydroxystearic acid, were identified (Fig. 4a).

The most efficient enzyme, ADH010, was subsequently used to validate the coupled assay with the canonical Ohy from Elisabethkingia meningoseptica (Em-OAH1) (Fig. 4b). It was found that a concentration of $0.1 \mathrm{mg} / \mathrm{ml} \mathrm{ADH010}$ (based on the weight of the lyophilised powder) was sufficient to detect the activity of $0.5 \mathrm{mg} / \mathrm{ml}$ (protein concentration) $E m-O A H 1$, but was limiting the activity at $2 \mathrm{mg} / \mathrm{ml}$ protein. By using a five times higher ADH concentration, the activity of both 0.5 and $2 \mathrm{mg} / \mathrm{ml} \mathrm{Em-OAH1}$ was measured successfully. Control measurements with only ADH or only Em-OAH1 showed no to minor background activity.

The kinetic parameters of RpOhy with oleic acid as substrate were determined using the novel coupled assay. In order

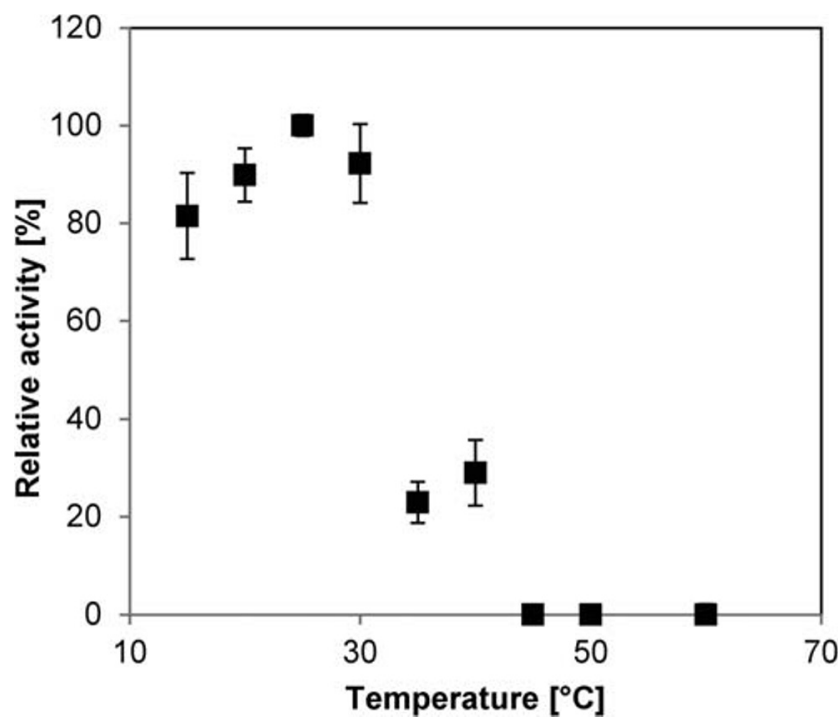

Fig. 2 Temperature tolerance with temperature optimum of $R p$ Ohy. Reactions (triplicates) were carried out in $20 \mathrm{mM}$ acetate buffer (pH 5) for $5 \mathrm{~h}$ at the respective temperatures. Reaction conditions: $5 \mu \mathrm{M}$ purified $R p$ Ohy, $500 \mu \mathrm{M}$ oleic acid with $1 \%$ DMSO as co-solvent and $20 \mu \mathrm{M}$ FAD. Relative activity is based on the highest absolute activity (here at $25^{\circ} \mathrm{C}$ ) and set to be $100 \%$

to ensure the ADH activity was not limiting in the coupled assay, a large excess of ADH was used, and the RpOhy concentration was at least 300-fold lower than the Em-OAH1 concentration that was used for the validation of the assay. The kinetic data followed a cooperative kinetics model with a $K_{0.5}$ value of $0.72 \pm 0.07 \mathrm{mM}$, a $V_{\max }$ of $17.5 \pm 1.4 \mathrm{U} / \mathrm{mg}$ and a Hill coefficient $n$ of $2.45 \pm 0.47$ (Fig. 4c).

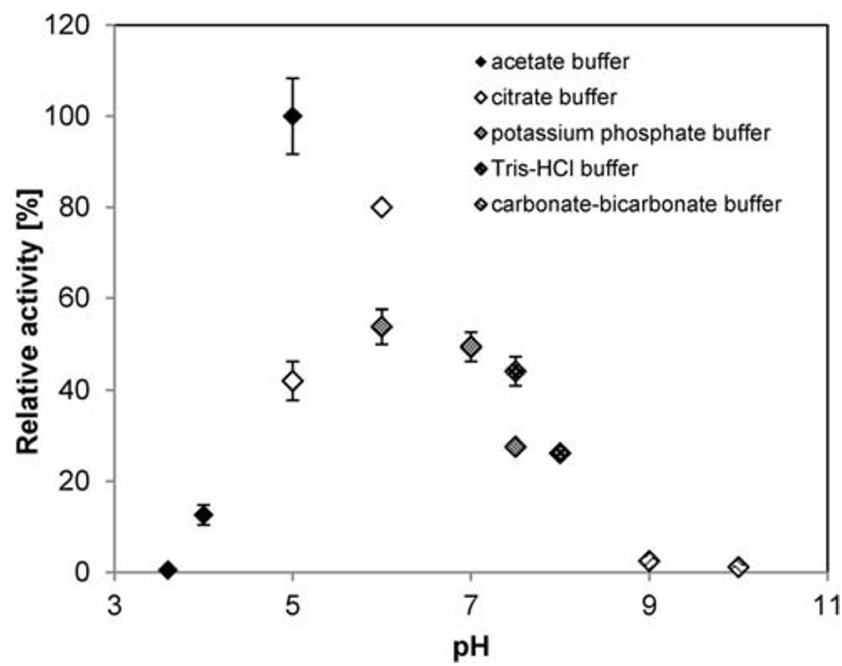

Fig. $3 \mathrm{pH}$ tolerance with $\mathrm{pH}$ optimum of $\mathrm{RpOhy}$. Reactions (triplicates) were carried out at $25^{\circ} \mathrm{C}$ for $5 \mathrm{~h}$ at the respective $\mathrm{pH}$ values. Reaction conditions: $5 \mu \mathrm{M}$ purified $R p$ Ohy, $500 \mu \mathrm{M}$ oleic acid with $1 \% \mathrm{DMSO}$ as co-solvent and $20 \mu \mathrm{M}$ FAD. Relative activity is based on the highest absolute activity (here in $20 \mathrm{mM}$ acetate buffer, $\mathrm{pH}$ 5) and set to be $100 \%$ 

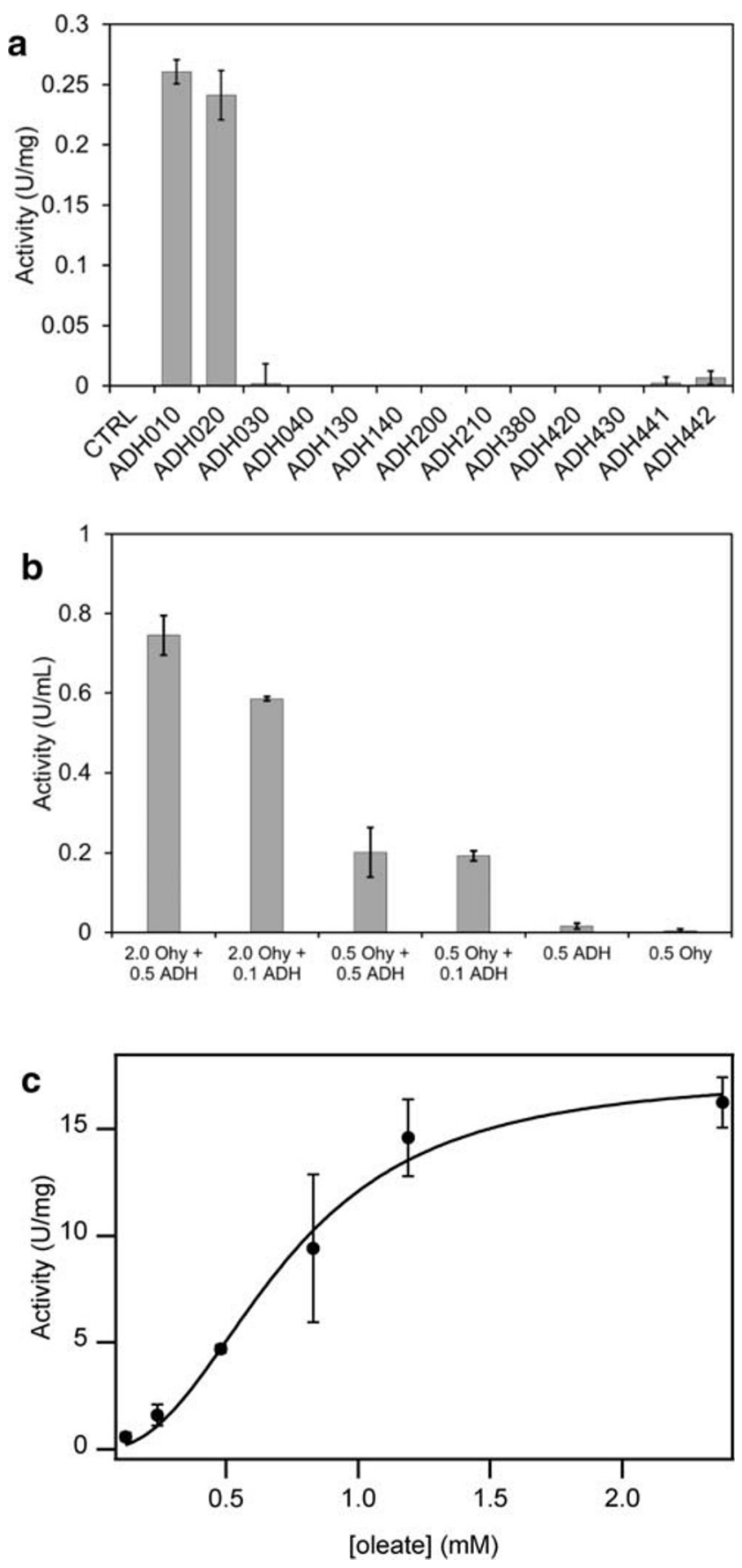

\section{Discussion}

\section{Diversity of Ohys in the genus Rhodococcus}

Genome analysis showed sequence diversity among Ohys that can be exploited for the discovery of novel features and will broaden future applications. Rhodococcus cells host a large number of interesting catabolic enzymes and are known for their extraordinary potential for bioremediation (Kim et al. 2018; Busch et al. 2020; Busch et al. 2019). The genus Rhodococcus was investigated in detail for the presence of
Fig. 4 Assay development and kinetics of RpOhy. a Screening of ADHs for the coupled assay of Ohy catalyzed conversion of oleic acid. Reaction conditions: $0.47 \mathrm{mg} / \mathrm{ml} \mathrm{ADH}$ (lyophilised powder), $2.5 \mathrm{mM} 10$ hydroxystearic acid, $2 \mathrm{mM} \mathrm{NAD}^{+}, 20 \mathrm{mM}$ PIPES buffer $\mathrm{pH} 6.5$ and $10 \%$ DMSO. b Validation of the Ohy-ADH coupled assay using Em-OAH1. Enzyme amounts below the horizontal axis are given in $\mathrm{mg} / \mathrm{ml}$ protein for $E m-O A H 1$ and $\mathrm{mg} / \mathrm{ml}$ lyophilised powder for AHD010. Reaction conditions: $0-0.5 \mathrm{mg} / \mathrm{ml} \mathrm{ADH010,} \mathrm{0-2} \mathrm{mg} / \mathrm{ml}$ Em-OAH1, $2.5 \mathrm{mM}$ oleic acid, $2 \mathrm{mM} \mathrm{NAD}{ }^{+}, 50 \mathrm{mM}$ PIPES buffer pH 6.5 and 10\% DMSO. c Apparent cooperative kinetics of $R p$ Ohy measured in a coupled assay with ADH010. Assay conditions: $0.125-$ $2.5 \mathrm{mM}$ oleic acid, $2 \mathrm{mM} \mathrm{NAD}^{+}, 50 \mathrm{mM}$ PIPES pH 6.5 and $10 \%$ DMSO, $0.3-1.5 \mu \mathrm{g} / \mathrm{ml} R p$ Ohy and $0.01-0.5 \mathrm{mg} / \mathrm{ml} \mathrm{ADH010}$. The solid line is a fit to the cooperative kinetics Hill equation $V_{0}=\frac{V_{\max } \cdot[S]^{n}}{K_{0.5}^{n}+[S]^{n}}$ with $K_{0.5}=$ $0.72 \pm 0.07 \mathrm{mM}$ and $V_{\max }=17.5 \pm 1.4 \mathrm{U} / \mathrm{mg}, n=2.45 \pm 0.47$

oleate hydratases using an Orthologous Matrix algorithm. From the analysis of 43 whole-genome sequences, 20 putative Ohys were identified clustered into three different clades. Sequence alignment and phylogenetic analysis revealed that each clade contained oleate hydratases from one specific family (HFam 1-3). Family-specific amino acid patterns were elucidated.

Recently, Schmid et al. described 80 highly conserved amino acids throughout all investigated Ohys (Schmid et al. 2016). While the function of some conserved amino acids is already known, others remain unknown. Up until now, all Ohys require FAD for a successful substrate conversion although the redox state of the cofactor is not changed during the reaction (Engleder and Pichler 2018). Currently, the scientific consensus is that the FAD cofactor only plays a structural role being essential for a correct positioning of amino acids in the active site (Engleder et al. 2015; Lorenzen et al. 2017). One sensitive sequence motif for the FAD cofactor binding region was identified as G69xG[LI][AG]x[LM][AS][AG]Ax[FY][LM][IV]R[DE][GA]x(3)Gxx[IV]x[IFVl][LFY]E96 (positions according to Em-OAH1) (Schmid et al. 2016). While all identified Ohys from HFam 1 (G14-E41) and HFam 3 (G13-G40) as well as HFam 2 Ohy from $R$. erythropolis DSM 43066 (G29-E56) share the same motif, the other Ohys in the 'pyridinivorans'clade differ distinctively in two of the conserved positions: T33 (instead of A (79\%) or G (11\%) (Schmid et al. 2016)) and S37 (instead of A (71\%), G (16\%) or T (8\%)) (positions 73 and 77 according to Em-OAH1)(Schmid et al. 2016) (Fig. S3). Especially threonine (T33) instead of Ala or Gly will increase the polarity. Additionally, amino acids R118-M123 (Em-OAH1) placed in a loop-region were shown to be involved in cofactor binding and catalysis (Engleder et al. 2015). While the HFam 2 clade shows a 'RGGREM' motif like Em-OAH1 (HFam 11, Fig. S4), Rhodococcus HFam 1 and HFam 3 Ohys all share a 'RGGRML' motif. In Em-OAH1, E122 takes an important role in the water activation step (Engleder et al. 2015) and based on the high motif similarity, it is likely that Rhodococcus HFam 2 Ohys react in a similar way. The other 
two groups, however, do not share the same motif and previous studies claimed a different reaction mechanism for HFam 3 Ohys (Lorenzen et al. 2017). Due to the same amino acid pattern, it is likely that Rhodococcus HFam 1 Ohys will react in the same way as HFam 3 Ohys.

Finally, residues 436 and 438 (numbering according to Em-OAH1) are involved in the binding of the carboxylate function of the substrate (Engleder et al. 2015; Lorenzen et al. 2017). At both positions, the probabilities of four different amino acids were described to be $54 \%$ T, $31 \%$ V, $8 \% \mathrm{~A}$ and $5 \% \mathrm{~S}$ (residue $436 \mathrm{Em}-\mathrm{OAH} 1$ ) and $48 \% \mathrm{~N}, 22 \% \mathrm{H}, 12 \%$ A and 9\% P (residue 438 Em-OAH1) (Schmid et al. 2016). Analysis of the two residues showed a distinct pattern depending on the chosen HFam (Fig. S5). While Rhodococcus Ohys from HFam 1 all show the combination of residues valine and alanine, Ohys in the pyridinivorans-clade all exhibit residues threonine and asparagine, respectively. HFam 3, on the other hand, displays amino acids valine and histidine. The latter residue was shown to be directly involved in the carboxylate binding in the case of Em-OAH1 as a single-point mutation from asparagine to alanine (N438A according to Em-OAH1) led to a reduced activity (Engleder et al. 2015). The presence of alanine in that position in the HFam 1 Ohys additionally hints at a different reaction mechanism for this group of enzymes. A recent study investigated the impact of these two amino acids on the final regio- and stereoselectivity and showed that selective mutations can lead to a complete reversal of selectivity with the example of the two fatty acid hydratases from Lactobacillus acidophilus (FA-HY1 and FA-HY2). Here, less bulky substituents in these two positions enabled the substrate to go deeper into the carboxylate end of the substrate channel (Eser et al. 2020).

The family-specific patterns could hint at different reaction mechanisms and explain the differences in substrate recognition. Docking studies with structural models based on published crystal structures from L. acidophilus NCFM for RpOhy and ReOhy (CCM2595) for ReOhy (PR4) were inconclusive due to the absence of FAD in the crystal structures which resulted in uncertainty of the position and configuration of the cofactor. The structure elucidation of $R p$ Ohy will give further insight in the HFam 2-specific reaction mechanism as well as further explain the differences in substrate acceptance.

\section{RpOhy and ReOhy (PR4) exhibit a complementary substrate scope}

Two representatives from HFam 2 and HFam 3, RpOhy and ReOhy (PR4), were chosen for heterologous expression in $E$. coli and tested on a large number of fatty acids using whole-cell biotransformations. When using the purified enzyme with shorter incubation times, no water addition was observed by Lorenzen et al. for ReOhy (CCM2595)
(Lorenzen et al. 2017). This example further shows the benefits of the more stable whole-cell system over the use of purified enzyme.

The two tested Ohys were found to act complementary with longer and sterically more demanding fatty acids. As expected, fatty acids palmitoleic acid and oleic acid were converted by both tested enzymes. Linoleic acid and $\gamma$-linolenic acid were also accepted by all Ohys, and water addition was exclusively observed in 10-position. The results from this screening are in alignment with the results obtained by Lorenzen et al. for ReOhy (CCM 2595) (Lorenzen et al. 2017). The all-cis-configurated pinolenic acid (18:3, cis$5,9,12$ ) was a substrate for both tested Rhodococcus Ohys. Here, the water addition was only observed in 10-position. Up to now, only two other Ohys from Lactobacillus acidophilus (NTV001 (FA-HY1) and LMG 11470) were shown to convert pinolenic acid whereby both catalyse the water addition in 13-position (Engleder et al. 2015; Hirata et al. 2015; Kim et al. 2015). This shows a clear preference for the 10-position over the 13-position for both Rhodococcus Ohys which can be explained by the two amino acids V393 and H395 (ReOhy (PR4)) and T390 and N392 (RpOhy) (corresponding to T436 and N438 in Em-OAH1) following the results from recent studies (Eser et al. 2020). In FA-HY1, these positions are occupied by two smaller serine amino acids meaning that the substrate is entering the substrate tunnel further leading to the water addition in 13-position (Eser et al. 2020). In our example, however, histidine and asparagine are bulkier thereby directing a water addition into 10-position. In general, the addition in 13-position was not detected with any of the tested substrates.

The tendency to convert large fatty acids could be explained by a larger active site in ReOhy (PR4). In this screening, ReOhy (PR4) was shown to even convert erucic acid in 14-position which, to our knowledge, has not been reported for any other Ohy. The active state as a monomer might have an influence on the ability to convert longer fatty acids. Surprisingly, both Ohys were not able to convert cis-vaccenic acid which has significant similarities with cis-11-eicosenoic acid but is two carbon atoms shorter. The absence of these two carbon atoms is most likely the reason why the shorter cisvaccenic acid is not accepted. Nervonic acid (24:1, cis-15) is possibly too long to fit in the active site of the proteins and trans-vaccenic acid does not reach the active site as the double bond is required to be cis-configurated as was reported earlier (Demming et al. 2018; Engleder and Pichler 2018).

Next to RpOhy, only two other hydratases (Lactobacillus plantarum AKU 1009a and Lysinibacillus fusiformis) were reported to show activity towards ricinoleic acid (Seo et al. 2013; Takeuchi et al. 2015). Its interesting emulsifying properties make 10,12-dihydroxystearic acid a potentially useful biosurfactant (Seo et al. 2013). FA-HY1 (Lactobacillus acidophilus) was described to also convert fatty acids 12 and 
13. However, the water addition for fatty acid 13 occurred in 15 -position while with fatty acid 12 , water addition took place in 12- and 15-position (Hirata et al. 2015).

This comprehensive substrate screening gives new insight into the capability of Ohys from Rhodococcus to convert a number of fatty acids selectively. It was shown that especially with more complex and unsaturated fatty acids, both investigated Ohys act complementary which can be further exploited for industrial applications. The described variety of the substrate scope of investigated Ohys is therefore consistent with the sequence variety among the different oleate hydratase families and members.

\section{RpOhy is a novel oleate hydratase}

RpOhy is active over a broad $\mathrm{pH}$ range ( $\mathrm{pH} 5-8)$ with an optimum at circa $\mathrm{pH} 6.5$ and temperature range $\left(15-40^{\circ} \mathrm{C}\right)$ with an optimum at circa $25^{\circ} \mathrm{C}$, which is comparable with the results obtained by Lorenzen et al. for ReOhy (CCM 2595) who described a temperature optimum at $28{ }^{\circ} \mathrm{C}$ and a $\mathrm{pH}$ optimum of 7.2 with good conversion rates in the range from pH 5-8 (Lorenzen et al. 2017).

The kinetics of $R p$ Ohy showed a significant cooperative effect, which has rarely been reported for Ohys. Only recently for Staphylococcus aureus Ohy, similar cooperative kinetics was reported with a similar Hill coefficient of $2.2 \pm 0.3$ (Subramanian et al. 2019). Most Ohys have been reported to display regular Michaelis-Menten kinetics with $K_{\mathrm{M}}$ in the range from 0.1 to $0.6 \mathrm{mM}$ and $V_{\max }$ from 0.6 to $4 \mathrm{U} / \mathrm{mg}$ (Bevers et al. 2009; Volkov et al. 2010; Rosberg-Cody et al. 2011; Joo et al. 2012a; Kim et al. 2012; Joo et al. 2012b). The reported values for $R e$ Ohy (CCM 2595) are $K_{\mathrm{M}}=0.49 \mathrm{mM}$ and $V_{\max }=1.27 \mathrm{U} / \mathrm{mg}$ (Lorenzen et al. 2017). The kinetic parameters for RpOhy suggest that this HFam 2 enzyme displays apparent cooperative kinetics and has a higher $V_{\max }$ than $R e$ Ohy (CCM 2595). However, due to the technical challenges of measuring the rate of conversion of a barely soluble substrate to an insoluble product, the activity measurements are strongly dependent on the precise conditions that have been used. It is therefore difficult to directly compare the parameters with the reported values for other Ohys that have been measured with different experimental conditions. Consequently, it is possible that the observed apparent cooperative kinetics does not reflect an allosteric effect on the enzyme by the substrate, but rather concentration-dependent substrate availability under the conditions that were used. Furthermore, the observed saturation of the activity at high substrate concentration may be affected by the critical micelle concentration of oleic acid.

\section{A novel oleate hydratase enzyme assay}

ADH010 has been reported to reduce 3-nonanone and AHD020 has been reported to reduce ethyl pyruvate by the enzyme manufacturer. Both enzymes have been reported to be inactive for the oxidation of rac-phenylalaninol (amino alcohol) and the reduction of 2-azidoacetophenone (azido ketone) (Mestrom et al. 2017; Schrittwieser et al. 2013). Interestingly, the reduced form of 3-nonanone, i.e. 3-nonanol, and 10-hydroxystearic acid share some resemblance as these are both secondary alcohols in a long aliphatic chain. Any reduced form of ethyl pyruvate does not have any apparent similarity to 10 hydroxystearic acid, which may imply that ADH020 has a broad substrate scope.

Secondary alcohol dehydrogenases that can oxidise 10hydroxystearic acid to 10 -ketostearic acid from Pseudomonas sp. NRLL B-3266 and from Nocardia cholesterolicum NRRL 5767 have been reported previously (Huang et al. 2020; Niehaus et al. 1978). Although preliminary reports have shown that cascade reactions with Ohy and ADHs are possible, these have never been used to develop an efficient Ohy activity assay (Koritala et al. 1989; Song et al. 2013). The ability to use NADH production to report Ohy activity is highly desired as it facilitates high throughput screening for Ohy activity and conversely enables directed evolution and other protein engineering approaches that are dependent on considerable screening efforts. We have successfully shown that the coupled assay can be used to measure the activity of $E m$-OAH1, RpOhy and most likely any Ohy. The method can be readily extended to other fatty acid hydratase substrates by searching for other optimal ADHs. Furthermore, the novel coupled assay will enable more extensive kinetic investigation of Ohys under many different conditions.

Acknowledgements This work is part of the Open Technology Programme with project number 14170 , which is financed by the Netherlands Organisation for Scientific Research (NWO) Domain Applied and Engineering Sciences. The authors thank Dr. Martin Schürmann for the supply of reference materials and methods. Nuria Campmany and Kasper Bergsma are acknowledged for practical assistance.

Author contributions Hanna Busch, Peter-Leon Hagedoorn and Ulf Hanefeld contributed to the study conception and design. Material preparation, data collection and analysis were performed by Hanna Busch, Fabio Tonin, Natália Alvarenga, Simona Lu and Marcel van den Broek. The first draft of the manuscript was written by Hanna Busch and PeterLeon Hagedoorn, Ulf Hanefeld and Jean-Marc Daran revised versions of the manuscript. All authors read and approved the final manuscript.

Funding information This study was funded by the Netherlands Organisation for Scientific Research (NWO) Domain Applied and Engineering Sciences (grant 14170).

\section{Compliance with ethical standards}

Conflict of interest The authors declare that they have no conflict of interest. 
Ethical approval This article does not contain any studies with human participants or animals performed by any of the authors.

Open Access This article is licensed under a Creative Commons Attribution 4.0 International License, which permits use, sharing, adaptation, distribution and reproduction in any medium or format, as long as you give appropriate credit to the original author(s) and the source, provide a link to the Creative Commons licence, and indicate if changes were made. The images or other third party material in this article are included in the article's Creative Commons licence, unless indicated otherwise in a credit line to the material. If material is not included in the article's Creative Commons licence and your intended use is not permitted by statutory regulation or exceeds the permitted use, you will need to obtain permission directly from the copyright holder. To view a copy of this licence, visit http://creativecommons.org/licenses/by/4.0/.

\section{References}

Altenhoff AM, Gil M, Gonnet GH, Dessimoz C (2013) Inferring hierarchical orthologous groups from orthologous gene pairs. PLoS One 8:e53786. https://doi.org/10.1371/journal.pone.0053786

Alvarez HM (2019) Biology of Rhodococcus, 2nd edn. Springer Nature Switzerland AG, Cham

Bankevich A, Nurk S, Antipov D, Gurevich AA, Dvorkin M, Kulikov AS, Lesin VM, Nikolenko SI, Pham S, Prjibelski AD, Pyshkin AV, Sirotkin AV, Vyahhi N, Tesler G, Alekseyev MA, Pevzner PA (2012) SPAdes: a new genome assembly algorithm and its applications to single-cell sequencing. J Comput Biol 19:455-477. https:// doi.org/10.1089/cmb.2012.0021

Bevers LE, Pinkse MWH, Verhaert PDEM, Hagen WR (2009) Oleate hydratase catalyzes the hydration of a nonactivated carbon-carbon bond. J Bacteriol 191:5010-5012. https://doi.org/10.1128/JB. 00306-09

Busch H, Hagedoorn PL, Hanefeld U (2019) Rhodococcus as versatile biocatalyst in organic synthesis. Int J Mol Sci 20:4787. https://doi. org/10.3390/ijms20194787

Busch H, Alvarenga N, Abdelraheem EMM, Hoek M, Hagedoorn PL, Hanefeld U (2020) Re-investigation of hydration potential of Rhodococcus whole-cell biocatalysts towards Michael-acceptors. ChemCatChem 12:193-198. https://doi.org/10.1002/cctc. 201901606

Demming RM, Otte KB, Nestl BM, Hauer B (2017) Optimized reaction conditions enable the hydration of non-natural substrates by the oleate hydratase from Elizabethkingia meningoseptica. ChemCatChem 9:758-766. https://doi.org/10.1002/cctc.201601329

Demming RM, Fischer MP, Schmid J, Hauer B (2018) (De)hydratasesrecent developments and future perspectives. Curr Opin Chem Biol 43:43-50. https://doi.org/10.1016/j.cbpa.2017.10.030

Edgar RC (2004) MUSCLE: multiple sequence alignment with high accuracy and high throughput. Nucleic Acids Res 32:1792-1797. https://doi.org/10.1093/nar/gkh340

Engleder M, Pichler H (2018) On the current role of hydratases in biocatalysis. Appl Biochem Biotechnol 102:5841-5858

Engleder M, Pavkov-Keller T, Emmerstorfer A, Hromic A, Schrempf S, Steinkellner G, Wriessnegger T, Leitner E, Strohmeier GA, Kaluzna I, Mink D, Schürmann M, Wallner S, Macheroux P, Gruber K, Pichler H (2015) Structure-based mechanism of oleate hydratase from Elizabethkingia meningoseptica. ChemBioChem 16:17301734. https://doi.org/10.1002/cbic.201500269

Engleder M, Strohmeier GA, Weber H, Steinkellner G, Leitner E, Müller M, Mink D, Schürmann M, Gruber K, Pichler H (2019) Evolving the promiscuity of Elizabethkingia meningoseptica oleate hydratase for the regio- and stereoselective hydration of oleic acid derivatives. Angew Chem Int Ed:58. https://doi.org/10.1002/anie.201901462

Eser BE, Poborsky M, Dai R, Kishino S, Ljubic A, Takeuchi M, Jacobsen C, Ogawa J, Kristensen P, Guo Z (2020) Rational engineering of hydratase from Lactobacillus acidophilus reveals critical residues directing substrate specificity and regioselectivity. ChemBioChem in press 21:550-563. https://doi.org/10.1002/cbic.201900389

Geer LY, Marchler-Bauer A, Geer RC, Han L, He J, He S, Liu C, Shi W, Bryant SH (2009) The NCBI BioSystems database. Nucleic Acids Res 38:D492-D496. https://doi.org/10.1093/nar/gkp858

Hirata A, Kishino S, Park S-B, Takeuchi M, Kitamura N, Ogawa J (2015) A novel unsaturated fatty acid hydratase toward C16 to C22 fatty acids from Lactobacillus acidophilus. J Lipid Res 56:1340-1350. https://doi.org/10.1194/jlr.m059444

Huang J-K, Samassekou K, Alhmadi HB, VanDerway DR, Diaz JD, Seiver JA, McClenahan SW, Holt SM, Wen L (2020) Knockout of secondary alcohol dehydrogenase in Nocardia cholesterolicum NRRL 5767 by CRISPR/Cas9 genome editing technology. PLoS One 15(3):e0230915. https://doi.org/10.1371/journal.pone.0230915

Jones AL, Goodfellow M (2012) Genus IV. Rhodococcus. In: Goodfellow M, Kämpfer P, Busse H-J, Trujillo ME, Ken-ichiro Suzuki WL, Whitman WB (eds) Bergey's manual of systematic bacteriology, 2nd edn. Springer, New York, pp 437-463

Joo Y-C, Jeong K-W, Yeom S-J, Kim Y-S, Kim Y, Oh D-K (2012a) Biochemical characterization and FAD-binding analysis of oleate hydratase from Macrococcus caseolyticus. Biochimie 94:907-915. https://doi.org/10.1016/j.biochi.2011.12.011

Joo Y-C, Seo E-S, Kim Y-S, Kim K-R, Park J-B, Oh D-K (2012b) Production of 10-hydroxystearic acid from oleic acid by whole cells of recombinant Escherichia coli containing oleate hydratase from Stenotrophomonas maltophilia. J Biotechnol 158:17-23. https://doi. org/10.1016/j.jbiotec.2012.01.002

Kim B-N, Joo Y-C, Kim Y-S, Kim K-R, Oh D-K (2012) Production of 10-hydroxystearic acid from oleic acid and olive oil hydrolyzate by an oleate hydratase from Lysinibacillus fusiformis. Appl Microbiol Biotechnol 95:929-937. https://doi.org/10.1007/s00253-011-38052

Kim KR, Oh HJ, Park CS, Hong SH, Park JY, Oh DK (2015) Unveiling of novel regio-selective fatty acid double bond hydratases from Lactobacillus acidophilus involved in the selective oxyfunctionalization of mono- and di-hydroxy fatty acids. Biotechnol Bioeng 112:2206-2213. https://doi.org/10.1002/bit. 25643

Kim D, Choi KY, Yoo M, Zylstra GJ, Kim E (2018) Biotechnological potential of Rhodococcus biodegradative pathways. J Microbiol Biotechnol 28:1037-1051. https://doi.org/10.4014/jmb.1712.12017

Koritala S, Hou CT, Hesseltine CW, Bagby MO (1989) Microbial conversion of oleic acid to 10-hydroxystearic acid. Appl Microbiol Biotechnol 32(3):299-304. https://doi.org/10.1007/BF00184978

Kumar S, Stecher G, Tamura K (2016) MEGA7: molecular evolutionary genetics analysis version 7.0 for bigger datasets. Mol Biol Evol 33: 1870-1874. https://doi.org/10.1093/molbev/msw054

Lorenzen J, Janke R, Waldow A, Qoura F, Loll B, Brück T (2017) Rhodococcus erythropolis oleate hydratase: a new member in the oleate hydratase family tree-biochemical and structural studies. ChemCatChem 10:407-414. https://doi.org/10.1002/cctc. 201701350

Mestrom L, Bracco P, Hanefeld U (2017) Amino aldehydes revisited. Eur J Org Chem 2017(47):7019-7025. https://doi.org/10.1002/ejoc. 201701213

Mimura A, Kawamo T, Yamaga K (1969a) Application of microorganisms to the petrochemical industry. I. Assimilation of nitrile compounds by microorganisms. J Ferment Technol 47:631-638

Mimura A, Kawano T, Yamaga K (1969b) Process for preparing specially activated sludge. US 3660278 
Niehaus WG, Frielle T, Kingsley EA (1978) Purification and characterization of a secondary alcohol dehydrogenase from a pseudomonad. J Bacteriol 134(1):177-183

Park AK, Lee GH, Kim DW, Jang EH, Kwon HT, Chi YM (2018) Crystal structure of oleate hydratase from Stenotrophomonas sp. KCTC 12332 reveals conformational plasticity surrounding the FAD binding site. Biochem Biophys Res Commun. https://doi.org/10.1016/j. bbrc.2018.03.220

Price MN, Dehal PS, Arkin AP (2010) FastTree 2-approximately maximum-likelihood trees for large alignments. PLoS One 5:e9490. https://doi.org/10.1371/journal.pone.0009490

Resch V, Hanefeld U (2015) The selective addition of water. Catal Sci Technol 5:1385-1399. https://doi.org/10.1039/c4cy00692e

Rosberg-Cody E, Liavonchanka A, Göbel C, Ross RP, O'Sullivan O, Fitzgerald GF, Feussner I, Stanton C (2011) Myosin-cross-reactive antigen (MCRA) protein from Bifidobacterium breve is a FADdependent fatty acid hydratase which has a function in stress protection. BMC Biochem 12:9. https://doi.org/10.1186/1471-2091-12-9

Schmid J, Steiner L, Fademrecht S, Pleiss J, Otte KB, Hauer B (2016) Biocatalytic study of novel oleate hydratases. J Mol Catal B Enzym 133:S243-S249. https://doi.org/10.1016/j.molcatb.2017.01.010

Schrittwieser JH, Coccia F, Kara S, Grischek B, Kroutil W, d'Alessandro N, Hollmann F (2013) One-pot combination of enzyme and Pd nanoparticle catalysis for the synthesis of enantiomerically pure 1 , 2-amino alcohols. Green Chem 15(12):3318-3331. https://doi.org/ 10.1039/C3GC41666F

Seemann T (2014) Prokka: rapid prokaryotic genome annotation. Bioinformatics 30:2068-2069. https://doi.org/10.1093/ bioinformatics/btu153

Seo MH, Kim KR, Oh DK (2013) Production of a novel compound, 10, 12-dihydroxystearic acid from ricinoleic acid by an oleate hydratase from Lysinibacillus fusiformis. Appl Microbiol Biotechnol 97: 8987-8995. https://doi.org/10.1007/s00253-013-4728-x

Serra S, De Simeis D, Castagna A, Valentino M (2020) The fatty-acid hydratase activity of the most common probiotic microorganisms. Catalysts 10(2):154. https://doi.org/10.3390/catal10020154

Song J-W, Jeon E-Y, Song D-H, Jang H-Y, Bornscheuer UT, Oh D-K, Park J-B (2013) Multistep enzymatic synthesis of long-chain $\alpha, \omega$ dicarboxylic and $\omega$-hydroxycarboxylic acids from renewable fatty acids and plant oils. Angew Chem Int Ed 52(9):2534-2537. https:// doi.org/10.1002/anie.201209187

Subramanian C, Frank MW, Batte JL, Whaley SG, Rock CO (2019) Oleate hydratase from Staphylococcus aureus protects against palmitoleic acid, the major antimicrobial fatty acid produced by mammalian skin. J Biol Chem 294:9285-9294. https://doi.org/10. 1074/jbc.RA119.008439

Takeuchi M, Kishino S, Hirata A, Park SB, Kitamura N, Ogawa J (2015) Characterization of the linoleic acid $\delta 9$ hydratase catalyzing the first step of polyunsaturated fatty acid saturation metabolism in Lactobacillus plantarum AKU 1009a. J Biosci Bioeng 119:636641. https://doi.org/10.1016/j.jbiosc.2014.10.022

Train CM, Glover NM, Gonnet GH, Altenhoff AM, Dessimoz C (2017) Orthologous Matrix (OMA) algorithm 2.0: more robust to asymmetric evolutionary rates and more scalable hierarchical orthologous group inference. Bioinformatics 33:i75-i82. https://doi.org/10. 1093/bioinformatics/btx229

van der Geize R, Dijkhuizen L (2004) Harnessing the catabolic diversity of Rhodococci for environmental and biotechnological applications. Curr Opin Microbiol 7:255-261. https://doi.org/10.1016/j.mib. 2004.04.001

Volkov A, Liavonchanka A, Kamneva O, Fiedler T, Goebel C, Kreikemeyer B, Feussner I (2010) Myosin cross-reactive antigen of Streptococcus pyogenes M49 encodes a fatty acid double bond hydratase that plays a role in oleic acid detoxification and bacterial virulence. J Biol Chem 285:10353-10361. https://doi.org/10.1074/ jbc.M109.081851

Volkov A, Khoshnevis S, Neumann P, Herrfurth C, Wohlwend D, Ficner R, Feussner I (2013) Crystal structure analysis of a fatty acid doublebond hydratase from Lactobacillus acidophilus. Acta Crystallogr D Biol Crystallogr 69:648-657. https://doi.org/10.1107/ S0907444913000991

Zampolli J, Zeaiter Z, Di Canito A, Di Gennaro P (2019) Genome analysis and -omics approaches provide new insights into the biodegradation potential of Rhodococcus. Appl Microbiol Biotechnol 103: 1069-1080. https://doi.org/10.1007/s00253-018-9539-7

Publisher's note Springer Nature remains neutral with regard to jurisdictional claims in published maps and institutional affiliations. 